Chirurg $2011 \cdot 82: 1124$

DOI 10.1007/s00104-011-2215-4

Online publiziert: 24. November 2011

(c) Springer-Verlag 2011

T. Kölbel · S. Wipper · H. Diener · E.S. Debus

Klinik und Poliklinik für Gefäßmedizin, Universitäres Herzzentrum Hamburg GmbH, Universitätskrankenhaus Eppendorf, Hamburg

\title{
Erratum zu: Endovaskuläre Therapie der chronisch mesenterialen Ischämie
}

\author{
Chirurg (2011) 82:880-886, \\ http://dx.doi.org/10.1007/s00104-011-2101-0
}

In diesem Beitrag wurde versehentlich

- Abb. 1b nicht dargestellt.

Wir bitten zukünftig die vollständige Abbildung zu berücksichtigen und den Fehler zu entschuldigen.

\section{Korrespondenzadresse}

PD Dr. T. Kölbel

Klinik und Poliklinik für Gefäßmedizin, Universitäres Herzzentrum Hamburg GmbH, Universitätskrankenhaus Eppendorf, Martinistr. 52, 20152 Hamburg tilokoelbel@googlemail.com
Abb. 1 - Versorgungsvarianten der arteriellen mesenterialen Strombahn. a Singulär abgehende A. lienalis (Pfeil). b Truncus hepaticomesentericus: die A. hepatica propria entspringt als 1. Ast der A. mesenterica superior (Pfeil). c Truncus coeliacomesentericus: gemeinsamer Abgang von Truncus coelicus und $A$. mesenterica superior (Pfeil). d Gemeinsamer Abgang der A. ileocolica und A. colica dextra als 4. Ast aus dem Truncus coeliacus (Pfeil)
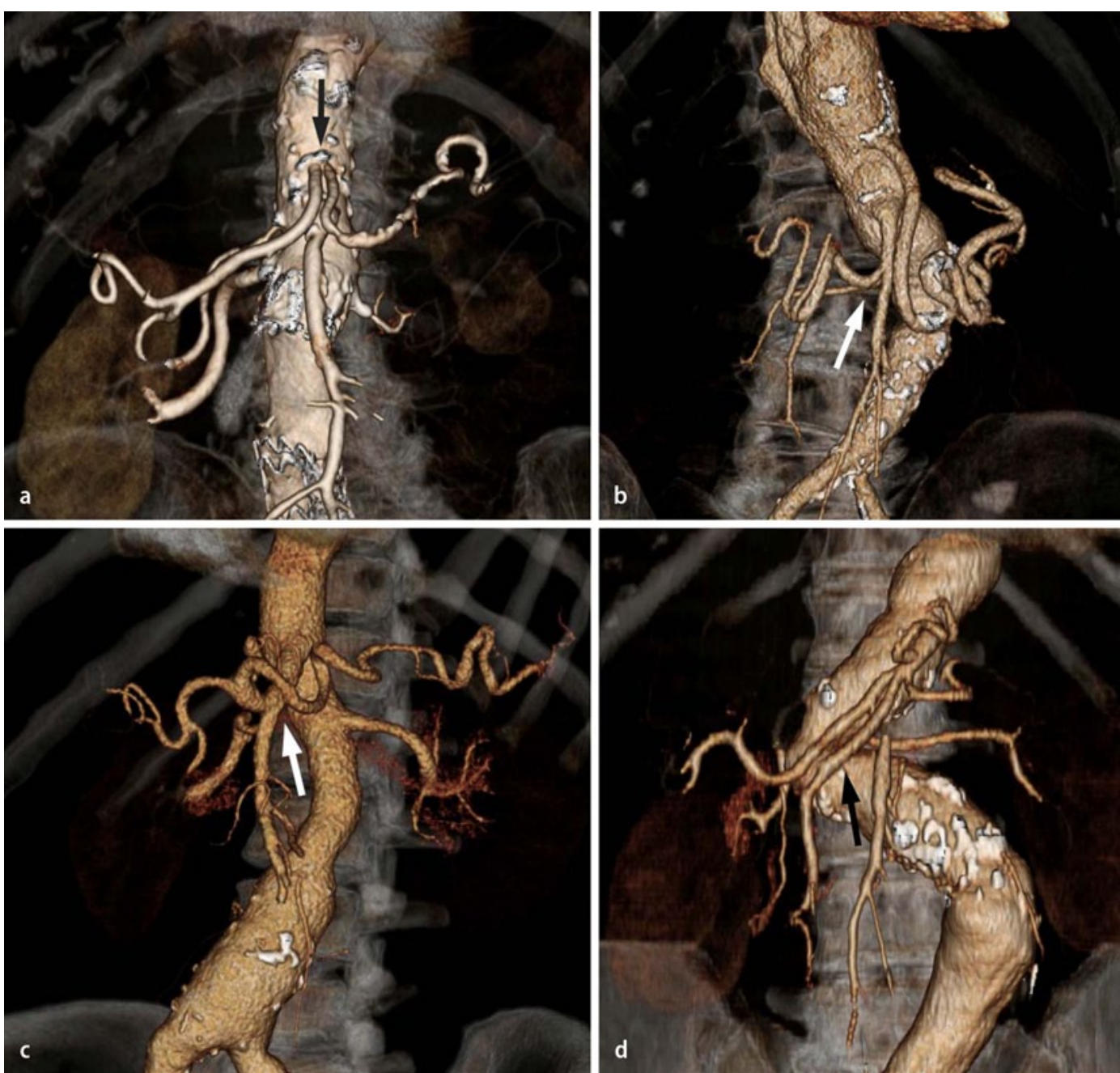